\title{
Non-isothermal sinter-crystallisation of satin glazes: a kinetic model
}

\author{
Amorós, J. L. ${ }^{1,2}$, Blasco, E. ${ }^{* 1}$, Moreno, A ${ }^{1,2}$, Gómez-Tena, M. P. ${ }^{1}$, Feliu, C. ${ }^{1,2}$ \\ ${ }^{1}$ Instituto de Tecnología Cerámica - Asociación de Investigación de las Industrias Cerámicas. \\ ${ }^{2}$ Department of Chemical Engineering. Universitat Jaume I, Campus Universitario Riu Sec, \\ 12006 Castellon, Spain. encarna.blasco@itc.uji.es
}

\begin{abstract}
Many materials of a glass-ceramic nature are obtained by glass particle sinter-crystallisation, whose process kinetics have been studied very little. The present study analyses the physicochemical transformations that develop during the firing of a complex commercial satin glaze (containing more than five phases), with high frit content, particularly focusing on sintercrystallisation kinetics. Glaze sintering and phase evolution were studied by hot stage microscopy (HSM) and X-ray diffraction (XRD). The glaze melting and crystallisation ranges and the kinetic parameters of the crystallisation process were determined by differential thermal analysis (DTA). Glaze sinter-crystallisation behaviour and the development of the crystal mass

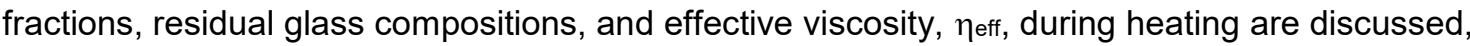
based on Rietveld analysis of the XRD data. A new kinetic model was developed that describes the non-isothermal sinter-crystallisation of materials exhibiting three-stage sintering. A two-step kinetic model is involved: sintering with concurrent surface crystallization (corresponding to sintering stages I and II) and sintering with simultaneous partial melting of crystalline phases (sintering stage III). The experimental data obtained by hot stage microscopy (HSM) at different heating rates were compared with those estimated by the model. The results obtained by the two methods exhibited very good agreement. The crystallisation kinetic parameters (activation energy, $E_{c r}$, and Avrami index, $n$, obtained by DTA, were consistent with the viscous flow activation energy, $Q_{2}$, corresponding to the first sintering step (sintering stages I and II). The model was used to calculate the values of the effective sintering viscosity, $\eta_{\mathrm{s}}$, of the glaze melt. These values were compared with the experimental effective viscosity, $\eta_{\text {eff, data obtained by hot }}$
\end{abstract}


stage microscopy (HSM). Both sets of results exhibited good agreement. Effective sintering viscosity, $\eta_{\mathrm{s}}$, which is readily measurable, helps better understand the role played by the different glaze constituents and by the firing conditions in sintering, enabling more rational design of these materials.

\section{Keywords: Sintering (A); Composites (B); Glass (D); Crystallization.}

\section{Introduction}

Good satin (and matt) glazes owe their appearance to microstructures with a significant crystalline phase content (about $40 \mathrm{wt} \%$ ), having crystal sizes ranging from 5 to $10 \mu \mathrm{m}$ dispersed in a glass matrix from which the crystals have devitrified during firing [1]. Simultaneous densification and crystalline phase formation of glass powders (sinter-crystallisation) is the main process that develops in the firing of this type of glaze composition, which mainly consists of frits (more than $70 \mathrm{wt} \%$ ) [2] [3]. The composition of these frits, which exhibit high crystallisability, their small particle size $(<40 \mu \mathrm{m})$, and the considerable number of crystalline particles (kaolin, feldspar, quartz) in the glaze, which act as heterogeneous crystallisation nuclei, favour surface devitrification without requiring the presence of nucleating agents or of thermal treatment for glass particle nucleation [1] [2] [3].

Fired glaze surfaces must contain no open pores. To achieve this, sintering of this type of glaze composition, despite having a high crystal content, must be practically complete. In many highly crystallisable compositions, intense crystal formation, often at the surface of glass particles, halts densification of the compact, including in initial and intermediate process phases. In these cases, to obtain dense materials, sintering needs to start again at higher temperatures, when the previously formed crystals begin to melt (secondary sintering). This yields a glaze with zero open porosity and high crystallinity [1] [2] [3]. The sintering of many glass-ceramic materials, such as glass from iron-rich industrial wastes [4] [5] or basaltic rocks [6] and bioactive glass [7], develops in this fashion.

The sintering (shrinkage-temperature) curve of these materials, in constant-rate heating experiments, consists of three main stages: an initial rapid densification stage at temperatures slightly above the glass transformation temperature $\left(T_{g}\right)$; a second stage, in which densification 
halts in a certain temperature range, usually associated with surface-induced devitrification; and finally, a second densification that starts with partial melting of the previously formed crystalline phases. No kinetic model appropriately describing the three sintering stages of these materials in constant-rate heating experiments is available in the literature to date. It was therefore deemed of interest to develop a kinetic model that describes this sintering behaviour. The twostep kinetic model obtained was validated by studying the sintering and crystallisation processes of a commercial satin glaze, widely used in wall and floor tile manufacture.

The glaze melting and crystallisation ranges, as well as the values of the crystallisation kinetic parameters (crystallisation activation energy, $E_{c r}$, and Avrami parameter, $n$, were obtained by differential thermal analysis (DTA) at different heating rates. The nature and quantity of the devitrifying phases were determined by $\mathrm{X}$-ray diffraction $(\mathrm{XRD})$ in test pieces fired at a heating rate of $25 \mathrm{~K} / \mathrm{min}$. Sintering kinetics were studied, continuously determining the sintering curve by hot stage microscopy (HSM), using different heating rates.

\section{Development of the model}

In a complex sintering process, in which densification develops in two separate steps, the overall process rate, $r$, is the sum of the rates corresponding to each step:

$$
r=r_{1}+r_{2} \quad \text { Eq. } 1
$$

In this case, $r_{1}$ is the sintering rate with concurrent surface crystallisation and $r_{2}$ is the sintering rate with simultaneous partial melting of the crystalline phases.

\section{i) Sintering with concurrent surface crystallisation}

The delaying effect of devitrification on glass sintering can be defined as the ratio: glass sintering rate/non-devitrifying glass sintering rate, under the same thermal treatment, $r_{1} / r_{0} \cdot$ In initial and intermediate sintering phases, when glass particle devitrification occurs at the surface (as is usually the case), the delaying effect may be assumed directly proportional to the glass particle surface fraction free of crystals, $\alpha_{g}[8]$. That is, 


$$
r_{1}=r_{0} \cdot \alpha_{g}
$$

According to this equation, sintering will halt when a thin, continuous layer of crystals has formed on the surface of the particles, even though neither the crystallisation nor the sintering process has ended.

By geometric arguments it may be deduced that $\alpha_{g}$ decreases as crystal average size, $r_{c}$, increases and/or the average distance between crystallisation nuclei, $\ell$, decreases (or as the surface density of these nuclei increases). The relationship between these characteristics, $\alpha_{g}=\alpha_{g}\left(r_{c}, \ell\right)$, is complex and depends, among other factors, on the distribution of the nuclei on the surface of the particles and on crystal size and shape distribution. In a first approach it may be assumed that $\alpha_{g}$ decreases exponentially as crystal size, $r_{c}$, increases and the distance between crystallisation nuclei, $\ell$, decreases according to an equation of the type:

$$
\alpha_{g}=\exp \left(-\kappa \cdot \frac{2 r_{c}}{\ell}\right)
$$

where $\kappa \geq 1$, a normalisation parameter that depends on the microstructural characteristics of the (glass or glass-ceramic) particle surface. Indeed, for spherical, homogeneous crystals of diameter $2 r_{c}$, which grow from regularly distributed nuclei at the nodal points of a square mesh (Figure 1a), for $\frac{2 r_{c}}{\ell}=1$, the glass particle surface free of (semi-sphere) crystals, $\alpha_{g}$, will be approximately 0.214 . According to Eq. 3 , the value of $\kappa$ for which this condition is obeyed will be close to 1.5. For other microstructures the value of $\kappa$ will be different. This relationship (Figure 1b) is similar to that initially deduced by Müller [8], based on statistical considerations, for a constant density of randomly distributed crystallisation nuclei.

According to Eq. 2 and Eq. 3, a high surface density of crystal nuclei, involving a low value of $\ell$, causes glaze sintering to halt at low crystal size, $r_{c}$, values and consequently also at low 
crystal surface layer thicknesses and low degrees of crystallisation progress. This behaviour has been experimentally verified [4] [7] [9].

Crystal size, $r_{c}$, depends on the degree of crystal growth. Assuming the crystal growth rate, $u$, for a certain material to vary with temperature in accordance with the Arrhenius relationship, one obtains:

$$
\frac{\mathrm{dr}_{\mathrm{c}}}{\mathrm{dt}}=\mathrm{u}=\mathrm{u}_{0} \cdot \exp \left(-\frac{\mathrm{Q}_{1}}{\mathrm{RT}}\right) \quad \text { Eq. } 4
$$

where $\mathrm{u}_{0}$ is the pre-exponential factor and $\mathrm{Q}_{1}$ the crystal growth activation energy, which must be similar to that of viscous flow in the crystallisation temperature range.

In experiments at constant-rate heating, $a=\frac{d T}{d t}$, Eq. 4 becomes:

$$
\frac{\mathrm{dr}_{\mathrm{c}}}{\mathrm{dT}}=\frac{\mathrm{u}_{0}}{\mathrm{a}} \cdot \exp \left(-\frac{\mathrm{Q}_{1}}{\mathrm{RT}}\right) \quad \text { Eq. } 5
$$

Separating variables in Eq. 5 and integrating yield:

$$
\mathrm{r}_{\mathrm{c}}=\frac{\mathrm{u}_{0}}{\mathrm{a}} \int_{0}^{\mathrm{T}} \exp \left(-\frac{\mathrm{Q}_{1}}{\mathrm{RT}}\right) \mathrm{dT} \quad \text { Eq. } 6
$$

Applying the Doyle approximation [10] to solve the temperature integral, one obtains:

$$
\int_{0}^{T} \exp \left(-\frac{Q_{1}}{R T}\right) d T=\frac{Q_{1}}{R} p\left(-\frac{Q_{1}}{R T}\right) \quad \text { Eq. } 7
$$

where 


$$
\log p\left(-\frac{Q_{1}}{R T}\right)=-2.315+0.457\left(-\frac{Q_{1}}{R T}\right) \quad \text { Eq. } 8
$$

It may be noted that this approximation only introduces a 3\% error in the solution of the temperature integral when $20 \leq\left(-\frac{Q_{1}}{R T}\right) \leq 60[11]$, a condition obeyed for this glaze as shown below.

From Eq. 6, Eq. 7, and Eq. 8 one obtains:

$$
r_{c}=\frac{k_{1}^{\prime}}{a} \exp \left(-\frac{Q_{1}}{R T}\right) \quad \text { Eq. } 9
$$

where $k_{1}^{\prime}$ is a constant independent of temperature and of the heating rate, $a$.

Introducing Eq. 9 in Eq. 3 and operating yields:

$$
\alpha_{g}=\exp \left(-\frac{k_{1}}{a} \cdot \exp \left(-\frac{Q_{1}}{R T}\right)\right) \quad \text { Eq. } 10
$$

On the other hand, the crystalline phase content in this type of glazes, when frit devitrification has not yet begun, is below $20 \%$ (Figure 2), so that sintering is by viscous flow and process kinetics must be similar to that of glass particle compacts. Indeed, it has been verified in glassceramic composites that, at low filler contents ( $<15 \%$ by volume), filler addition hardly modifies the sintering behaviour of the glass particle compact [12] [13]. Consequently, the glaze sintering rate, without the delaying effect of devitrification, $r_{0}$, may be deemed that of a glass particle compact. One of the simplest equations, applicable to jagged (ball milled) glass particles, which describes the variation of the firing shrinkage of a glass particle compact during isothermal sintering very well, is the Exner and Giess model [14] [15] [16]: 


$$
r_{0}=\frac{d X}{d t}=(1-X) \frac{\pi}{d_{0}} \cdot \frac{1}{\left(1-\rho_{0}^{1 / 3}\right)} \cdot \frac{\gamma}{\eta(T)}
$$

where:

$X=$ sintering degree of advance; ratio: firing shrinkage/maximum firing shrinkage.

$\mathrm{d}_{0}=$ average particle size $(\mathrm{m})$.

$\rho_{0}=$ initial compactness of the particle bed.

$\gamma=$ glass surface tension $(\mathrm{N} \cdot \mathrm{m}-1)$.

$\eta(T)=$ glass viscosity $(\mathrm{Pa} \cdot \mathrm{s})$

If the effect of temperature on process rate, $r_{0}$, is assumed to be due to the effect of temperature on glass viscosity, $\eta(T)$, and this effect, in a first approximation, is of an Arrhenius type, Eq. 11 becomes:

$$
\begin{aligned}
r_{0}=\frac{d X}{d t} & =(1-X) \cdot \frac{\pi}{d_{0}} \cdot \frac{1}{\left(1-\rho_{0}^{1 / 3}\right)} \cdot \frac{\gamma}{\eta_{0}} \cdot \exp \left(-\frac{Q_{2}}{R T}\right) \\
& =(1-X) \cdot k_{2} \cdot \exp \left(-\frac{Q_{2}}{R T}\right)
\end{aligned}
$$

where $\mathrm{k}_{2}$ is a constant independent of the thermal treatment involved.

In experiments at constant-rate heating, $a=\frac{d T}{d t}$, Eq. 2, Eq. 10, and Eq. 12 yield:

$$
\begin{aligned}
\left(\frac{d X}{d T}\right)_{1} & =\frac{r_{1}}{a}=\frac{r_{0}}{a} \alpha_{g}=(1-X) \cdot \frac{k_{2}}{a} \cdot \exp \left(-\frac{Q_{2}}{R T}\right) \cdot \alpha_{g} \\
& =(1-X) \cdot \frac{k_{2}}{a} \cdot \exp \left(-\frac{Q_{2}}{R T}\right) \cdot\left\{\exp \left[-\frac{k_{1}}{a} \cdot \exp \left(-\frac{Q_{1}}{R T}\right)\right]\right\}
\end{aligned}
$$


ii) Sintering with simultaneous partial melting of crystalline phases

During the heating of these glazes with a high surface density of crystallisation nuclei in the crystallisation temperature range, crystalline phase content increases, so that the material's effective or apparent viscosity, $\eta_{c}$, also rises (though glassy phase viscosity, $\eta(T)$, decreases). As a result, sintering, which had already halted at the onset of the crystallisation process, will only start again when this last process ends and the crystals formed begin to melt. Therefore, in this melting onset phase, the glaze may be deemed a porous glass-ceramic, whose microstructural characteristics will depend, if thermal treatment is at constant-rate heating, $a$, on the value of this variable. Generally, as the heating rate increases, crystalline phase content will decrease [17].

In a first approach, the sintering rate, $r_{2}$, of a porous glass-ceramic is also assumed to be of order 1 , as in i), and inversely proportional to its effective viscosity, $\eta_{\mathrm{c}}$. Thus:

$$
r_{2}=\frac{d X}{d t} \alpha(1-X) \cdot \frac{1}{\eta_{c}} \quad \text { Eq. } 14
$$

The effective viscosity, $\eta_{c}$, of glass-ceramic materials is usually expressed as the product of glass matrix viscosity, $\eta(T)$, which depends on temperature and glass matrix composition, and relative viscosity, $\eta_{\mathrm{r}}$.

$$
\eta_{\mathrm{c}}=\eta \eta_{\mathrm{r}}
$$

Relative viscosity, $\eta_{\mathrm{r}}$, in turn, is a function of crystal volume fraction, $\phi$, and crystal microstructural characteristics (crystal shape and amplitude of size distribution). One of the most widely used relationships is the Krieger relationship [18]:

$$
\eta_{r}=\left(1-\frac{\phi}{\phi_{\max }}\right)^{-m}
$$


where $\phi_{\max }$ is the maximum packing fraction of crystals, which depends mainly on the crystal shape and amplitude of size distribution; and $\mathrm{m}$ is a parameter that mainly depends on crystal shape. For glass-zircon composites [19], glass-alumina composites [20], and complex glaze compositions [21], values have been obtained of $0.60 \leq \phi_{\max } \leq 0.74$ and $\mathrm{m}=4.5$.

In a first approach, it may be assumed that, on changing the heating rate, a, and/or temperature, crystalline phase content, $\phi$, will change but crystal shape and the amplitude of size distribution will remain unaltered, so that $\eta_{r}$, according to Eq. 16, will only be a function of $\phi$ (and not of $\phi_{\max }$ or $\mathrm{m}$ ). Thus, the effect of temperature and heating rate on $\eta_{r}$ will only be due to the effect of these variables on $\phi$. In addition, since the liquid phase content increases exponentially with temperature ( $\phi$ decreases, following the same trend), as was verified for this glaze (Figure 2), $\eta_{\mathrm{r}}$ will also decrease in a practically exponential form with this variable, as may be verified mathematically. The function $\eta_{r}=(a, T)$ may therefore be simply expressed as follows:

$$
\eta_{r}(a, T)=\eta_{r_{0}}(a) \cdot \exp \left(\frac{Q^{\prime}(a)}{R T}\right) \quad \text { Eq. } 17
$$

With regard to the viscosity of the glass matrix, as in the previous step, i), this is only deemed to be a function of temperature, following an Arrhenius-type relationship:

$$
\eta(T)=\eta_{0} \exp \left(\frac{Q^{\prime}}{R T}\right) \quad \text { Eq. } 18
$$

Eq. 14, Eq. 15, Eq. 17, and Eq. 18 yield:

$$
\left(\frac{d X}{d T}\right)_{2}=\frac{r_{2}}{a}=k_{3}(a) \cdot \exp \left(-\frac{Q^{\prime}(a)}{R T}\right) \cdot \exp \left(-\frac{Q^{\prime \prime}}{R T}\right) \cdot(1-X) \quad \text { Eq. } 19
$$

Or: 


$$
\left(\frac{d X}{d T}\right)_{2}=k_{3}(a) \cdot \exp \left(-\frac{Q_{3}(a)}{R T}\right) \cdot(1-X) \quad \text { Eq. } 20
$$

where: $Q_{3}(a)=Q^{\prime}(a)+Q^{\prime \prime}$.

In this case, the apparent activation energy of this second sintering step, $Q_{3}(a)$, besides varying with heating rate, will be much larger than $Q_{1}$ or $Q_{2}$, whose values will be similar to $Q^{\prime \prime}$ and to those of viscous flow activation energy.

Eq. 1, Eq. 13, and Eq. 20 yield:

$$
\frac{d X}{(1-X) d T}=\frac{k_{2}}{a} \cdot \exp \left(-\frac{Q_{2}}{R T}\right) \cdot \exp \left[-\frac{k_{1}}{a} \cdot \exp \left(-\frac{Q_{1}}{R T}\right)\right]+k_{3}(a) \cdot \exp \left(-\frac{Q_{3}(a)}{R T}\right) \quad \text { Eq. } 21
$$

In accordance with Eq. 21, the sintering rate of a glaze with concurrent crystallisation and partial melting of crystalline phases is the sum of two contributions: a) first term of the second member, due to sintering of the glass matrix, which partially devitrifies (generally by a surface crystallisation mechanism), and b) second term of the second member, due to sintering of a glass-ceramic composite, in which the previously formed crystals dissolve in the melt.

The temperature ranges in which each of these two contributions predominate are determined by the six kinetic parameters $\left(k_{i}\right.$ and $\left.Q_{i}\right)$ in Eq. 21 .

\section{Experimental}

The study was conducted with a commercial satin glaze composition used as a floor tile coating, mainly consisting of a frit (about 70wt\%) with high commercial $\mathrm{Ca}, \mathrm{Zn}, \mathrm{Ba}$, sodium-potassium feldspar, and kaolin contents. The chemical composition of the glaze is detailed in Table 1. Cylindrical test pieces, about $5 \mathrm{~mm}$ in diameter and $5 \mathrm{~mm}$ thick, were pressed at $50 \mathrm{MPa}$ from a glaze powder with an average particle size of $7.6 \mu \mathrm{m}$. All particles were below $40 \mu \mathrm{m}$. The sintering and melting curves were determined from the test piece silhouettes by heating microscopy (HSM), at heating rates ranging from 0.5 to $60 \mathrm{~K} / \mathrm{min}$. 
The volumetric shrinkage strain, $\varepsilon_{\mathrm{d}}$, was calculated by assuming that shrinkage was isometric. The degree of sintering progress, $\mathrm{X}$, was calculated from the equation:

$$
X=\frac{\ln \left(A / A_{0}\right)}{\ln \left(A_{\min } / A_{0}\right)}
$$

where $A_{0}, A$, and $A_{\min }$ are the initial, instantaneous, and minimum silhouette surface areas, respectively.

The fixed viscosity points of the glaze were determined from the shape of the test piece silhouette in the HSM test. Glaze DTA curves were determined at heating rates ranging from 5 to $60 \mathrm{~K} / \mathrm{min}$.

The temperature values of the maximum crystallisation rate, $T_{p}$, corresponding to different heating rates, a, were used to calculate the crystallisation activation energy, $E_{c r}$, by applying the Kissinger method [22], i.e. fitting the pairs of values $\left(T_{p}\right.$, a) to the equation:

$$
\ln \left(\frac{a}{T_{p}^{2}}\right)=-\frac{E_{c r}}{R T_{p}}+\text { cst. }
$$

where $E_{c r}$ is the activation energy of the crystallisation process.

The Avrami parameter, $\mathrm{n}$, which for a constant number of nucleation sites is the growth dimensionality, was determined from the Ozawa equation [23]:

$$
\left\{\frac{\mathrm{d}[\ln (-\ln (1-\alpha))]}{\mathrm{d}(\ln \mathrm{a})}\right\}_{\mathrm{T}^{\prime}}=-\mathrm{n} \quad \text { Eq. } 24
$$

where the degree of crystallization, $\alpha$, is determined at a fixed temperature, $T^{\prime}$, from exotherm peaks obtained at different heating rates, a; $\alpha$ is calculated as the ratio of partial area of the crystallization peak at $\mathrm{T}^{\prime}$ to its total area. 
The nature and content of the crystalline phases that developed in the glaze as a function of temperature were determined from cylindrical test pieces, $2 \mathrm{~cm}$ in diameter and $0.5 \mathrm{~cm}$ thick, pressed at a pressure of $60 \mathrm{MPa}$ and fired at a rate of $25 \mathrm{~K} / \mathrm{min}$ to different peak temperatures. The phases in the fired test pieces were determined by XRD, applying the Rietveld method [24].

\section{Results and discussion}

\subsection{Behaviour of the glaze composition at $25 \mathrm{~K} / \mathrm{min}$}

i) Dissolution and crystallisation phenomena

The nature and development of the crystalline phase content with firing temperature reflect the complexity of this glaze composition (Table 2). In every case, the agreement between the experimental data and the values estimated by the Rietveld method was good $\left(R_{w p}<8\right)$. Figure 2 shows the results, grouped in the form: residual crystalline phases (kaolinite, nepheline, albite, and microcline), crystalline phases formed during firing (hyalophane, willemite, anorthite, and anorthoclase), and amorphous phase calculated from the difference.

At low temperature $\left(600-700^{\circ} \mathrm{C}\right)$, the glaze consisted mainly of a high percentage ( $\left.80 \mathrm{wt} \%\right)$ of amorphous material (starting frit + resulting amorphous material from kaolin decomposition) and considerable amounts of nepheline, microcline, and albite. Above $800^{\circ} \mathrm{C}$, the reaction between these crystalline phases and the glass matrix (frit), rich in alkaline earths and zinc, led to the formation of plagioclase, mainly anorthite, and to a decrease in nepheline and microcline. The calcium plagioclase probably also formed by reaction between the frit and the amorphous phase resulting from kaolin decomposition. The similarity in crystal structure of the albite and anorthite, evidenced, among other characteristics, by the superimposition of the diffraction peaks, made it difficult to determine their relative amounts, even with the Rietveld method.

Concurrent to these transformations, abrupt and abundant crystallisation of hyalophane and anorthoclase and, to a lesser extent, of willemite took place.

The crystal phase content peaked at about $1000^{\circ} \mathrm{C}$. Willemite and anorthite began to dissolve progressively in the melt at higher temperature and, at the studied glaze firing temperature $\left(1140^{\circ} \mathrm{C}\right)$, willemite and anorthite content was already small. 
In contrast, abundant hyalophane and anorthoclase developed and varied very little between $900^{\circ} \mathrm{C}$ and $1100^{\circ} \mathrm{C}$. At $1140^{\circ} \mathrm{C}$, the hyalophane and anorthoclase crystal content was still high ( 40wt\%). This characteristic, together with the morphology and size of these crystals (mainly between $5 \mu \mathrm{m}$ and $10 \mu \mathrm{m}$ ) (Figure 3), provided the fired glaze with its satin finish.

\section{ii) Sintering}

The complex development of these glaze phases during firing suggests that the sintering process is equally complex. Indeed, the sintering curve, i.e. the variation of volumetric shrinkage strain, $\varepsilon_{\mathrm{d}}$, with temperature (which displays a sigmoidal shape for most materials with a high glassy phase content), was here made up of three sections (Figure 4). For the sake of clarity, the sintering rate, $\mathrm{d} \varepsilon_{\mathrm{d}} / \mathrm{dT}$, and the DTA thermogram have also been plotted in this figure.

The first section ran from $750^{\circ} \mathrm{C}$, i.e. slightly above the glass transformation temperature $\left(T_{g}\right.$ in Figure 4), to the peak crystallisation temperature $\left(T_{p}\right.$ in Figure 4$)$ at about $900^{\circ} \mathrm{C}$. It shows that the densification rate increased as temperature rose until the frit began to crystallise ( $T_{x}$ in Figure 4). This was mainly due to the decrease in viscosity of the amorphous phase with rising temperature, as amorphous phase content, about $70-80 \mathrm{wt} \%$, remained practically constant in this temperature range. The sintering rate decreased progressively between $T_{x}$ and $T_{p}$, until it cancelled out, owing to the increase in effective viscosity of the system as the crystal volume fraction advanced (Figure 2). At this stage of the process, the initially amorphous or glassy particle surface fraction became progressively saturated with crystals, as had been assumed in the development of the model. Between the peak crystallisation temperature, $T_{p}$, and melting onset temperature, $\mathrm{T}_{\text {if, }}$, at about $1000^{\circ} \mathrm{C}$, the glaze did not sinter because, in this temperature range, on the one hand, the crystal content was very high, 70wt\% (Figure 2) and, consequently, in accordance with Eq. 16, system viscosity, $\eta_{\mathrm{c}}$, was infinite. On the other hand, the glass particle surfaces were practically saturated with crystals, $\alpha_{s}$. Sintering started again close to $1030^{\circ} \mathrm{C}$ (sintering stage III). At this temperature close to melting onset temperature, $\mathrm{T}_{\text {if, }}$ the crystals that had formed began to dissolve in the melt (Figure 2), thus progressively raising glassy phase content, with increasingly lower glassy phase viscosity, as temperature rose. This led to a sharp increase in the sintering rate. Only at temperatures close to peak densification 
temperature $\left(\sim 1100^{\circ} \mathrm{C}\right)$, the final sintering stage, did the sintering rate decrease, which also occurred abruptly, until it cancelled out.

iii) Residual glass

The dissolution and crystallisation phenomena discussed above determined residual glass quantity and composition, as well as glaze viscosity. The residual glass composition was estimated for each sample in Table 2 from the crystal phase content, assuming an ideal stoichiometric composition of the crystals. The calculated molar composition data are shown in Figure 5. All fluxing oxides with a valency of +1 and +2 have been grouped in the $\mathrm{M}_{2} \mathrm{O}+\mathrm{MO}$ corner of the composition triangle. It may be observed that, as glassy phase content decreased with increasing temperature from $800^{\circ} \mathrm{C}$ to $1000^{\circ} \mathrm{C}$, owing to crystallisation of new phases, the glass composition became poorer in silica and alumina. When the temperature rose above $1000^{\circ} \mathrm{C}$, the silica and alumina content increased again, owing to melting of the crystalline phases. Treating all fluxing oxides together, besides simplifying the representation of the residual glass composition, also minimised the effect on the residual glass composition of the crystalline phases that deviated to a greater or lesser extent from their ideal stoichiometry, as often occurs in the case of hyalophane, anorthite, anorthoclase, etc. These results indicate that, though glass viscosity decreased considerably, owing to the change in glass composition (decreased silica and alumina content) and higher temperature, the considerable increase in system viscosity resulting from surface crystallisation of the glass matrix was so high that it halted glaze sintering (Figure 4).

\subsection{Effect of the heating rate, a, on glaze behaviour}

The pronounced effect of the heating rate on the range of temperatures in which the glaze crystallisation process developed, in turn, determined the temperature range in which each of the sintering curve sections were located (Table 3 and Figure 6). Indeed, as reported in the literature [25], [26], a reduction in the heating rate, a, considerably lowered the crystallisation onset temperature, $T_{x}$, and maximum crystallisation rate temperature, $T_{p}$. In our case, the onset

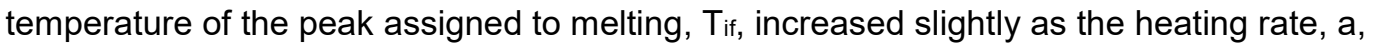
decreased, presumably associated with the formation of a larger quantity of crystals. 
Consequently, the decrease in crystallisation onset temperature, $T_{x}$, and the increase in melting onset temperature, $\mathrm{T}_{\mathrm{if}}$, with the reduction in heating rate, $\mathrm{a}$, led to the following effects (Figure 6): lengthening of section II (higher values of the difference $\left.T_{i}(I I I)-T_{f}(I)\right)$; decreased degree of sintering at which this developed; and greater effect of temperature on sintering in section III (slope of section III).

\subsection{Verification of the model}

Eq. 21 was integrated by the Runge-Kutta 4th order method. As may be observed (Figure 6), the fit of the experimental results to Eq. 21 was very good. The activation energy of crystal growth, $Q_{1}$, and of sintering in the initial stage, $Q_{2}$, was very similar (Table 4), in accordance with the literature [8]. This result suggests that the effect of temperature on the rate at which both processes (sintering and crystallisation) developed was due to the effect of temperature on the viscosity of the glass matrix. Indeed, if the crystallisation process takes place at the surface, as assumed in the model developed, crystallisation activation energy, $E_{c r}$, must be very similar to crystal growth activation energy, $\mathrm{E}_{\mathrm{G}}$, and comparable, in turn, to viscous flow activation energy, $E_{\eta}$.

Therefore, to confirm this assumption, using the DTA data, crystallisation activation energy, $E_{c r}$, was determined from the Kissinger equation (Eq. 23) (Figure 7), while the Avrami parameter, $\mathrm{n}$, was determined from the Ozawa equation (Eq. 24) (Figure 8). The average value $n=1.2$ obtained, close to 1, indicates, in accordance with the formal theory of transformation kinetics developed by Kolmogorov-Johnson-Mehl-Avrami (“KJMAE”) [27], that crystallisation was mainly surface induced and one-dimensional crystals could form. Similar results were obtained by A. Karamanov [4]. In addition, in this case, the value of Ecr obtained by DTA must match that of crystal growth, $E_{G}$, and that of viscous flow, $E_{\eta}$.

The value obtained from the DTA data, $E_{\mathrm{cr}} \approx \mathrm{E}_{\mathrm{G}} \approx \mathrm{E} \eta_{\eta}=385 \pm 23 \mathrm{~kJ} / \mathrm{mol}$, was verified to be very similar to that obtained by judiciously applying the developed model to the sintering experiments, $Q_{1}=405 \mathrm{~kJ} / \mathrm{mol}$ (Table 4), again confirming the validity of the developed model as

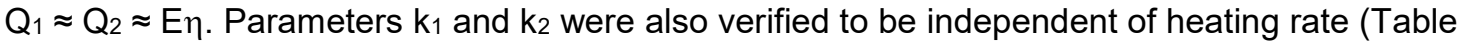
4), which was also in accordance with the developed model. 
On the other hand, sintering activation energy in the high temperature range, $Q_{3}(a)$, and $k_{3}(a)$ decreased as the heating rate increased, $\mathrm{k}_{3}$ depending considerably on the heating rate $\left(\mathrm{k}_{3} \alpha 1 / \mathrm{a}^{3}\right)$ (Figure 9), as assumed in the model. This was because, as the heating rate decreased, the quantity of devitrified crystalline phases in the sample increased before sintering started again. This behaviour led to sintering halt at increasingly lower values of the degree of advance, $\mathrm{X}$, (horizontal sections in Figure 6) and to lengthening of these sections, as mentioned above. Crystalline phase melting thus became more pronounced as the heating rate decreased, and the variation of system effective viscosity with temperature and the sintering rate therefore also evolved analogously. In addition, $Q_{3}(a)$ was much larger than $Q_{2}$ and $Q_{1}$, because the apparent activation energy of secondary sintering takes into account the combined effect of temperature on the decrease in crystalline phase content, $Q^{\prime}(a)$, and on the viscosity of the glass matrix, Q", in accordance with the assumed model.

\subsection{Effective sintering viscosity, $\eta_{s}$, of the glaze melt}

Clearing $\eta(T)$ in Eq. 11 yields:

$$
\eta(T)=\left[\frac{d X}{(1-X) \cdot d T}\right]^{-1} \cdot\left[\frac{\pi \cdot \gamma}{a \cdot d_{0}\left(1-\rho_{0}^{1 / 3}\right)}\right] \quad \text { Eq. } 25
$$

This expression allows viscosity, $\eta(T)$, to be estimated for glasses, determining the values of the first term of the second member in constant-rate heating experiments. The values of the second factor of the second member do not depend on temperature and can be readily estimated or determined.

However, this equation can also be used to estimate the effective viscosity of any material sintering by viscous flow, from the sintering data, $\eta_{s}$. In this case, assuming process kinetics to be of order 1 (Eq. 11), all variations in the sintering rate of a material with temperature, as in the studied glaze (Figure 4), must stem from the variations of the system's effective viscosity, $\eta_{\mathrm{s}}$, with temperature. This approach is very useful in studying and interpreting the sintering of glazes and glass-ceramics with complex compositions. In these materials, the rate at which 
densification and melting develops depends on the rate at which other transformations such as glass matrix devitrification and crystal melting occur, which substantially modify not only glassy phase content but also its viscosity and hence system (glass + crystals) effective viscosity.

Figure 10 shows the effective viscosity-temperature, $\eta_{\text {eff }}(T)$, curve corresponding to the studied glaze at a heating rate of $a=25 \mathrm{~K} / \mathrm{min}$, obtained from the values of the fixed viscosity points determined by HSM, assigning, to each point, the viscosity value suggested by different authors [28] [29] [30] [31]. Owing to abundant phase crystallisation, the fixed viscosity point assigned at sintering end was observed to shift more than $200^{\circ} \mathrm{C}$ higher. The viscosity values assigned by these researchers exhibited a certain scatter at each fixed point. The figure also shows the effective sintering viscosity-temperature, $\eta_{s}(T)$, curve, replacing the first term of the second member of Eq. 25 with the values obtained on applying the developed model (first term of Eq. 21), using the kinetic parameters $\left(k_{i}\right.$ and $\left.Q_{i}\right)$ detailed in Table 4 and Figure 9. An average value was estimated for surface tension, $\gamma=0.365 \mathrm{~N} / \mathrm{m}$, as the glass composition varied with temperature, in accordance with Goleus [32]. In the range of temperatures in which glaze densification halted (section II), the effective sintering viscosity $\left(\eta_{s}\right)$ vs. temperature curve was observed to exhibit a maximum that practically coincided with that of the DTA peak corresponding to phase crystallisation (Figure 4). Figure 10 also shows the effective sintering viscosity vs. temperature curve that the glaze would follow if no devitrification were assumed to take place. To do so, in Eq. 21 the values of $k_{2}$ and $k_{3}$ were assumed to be zero. Comparison of the two curves clearly evidences the pronounced effect of devitrification on glaze melt viscosity, as this even halted sintering. Good agreement is also observed between the effective sintering viscosity, $\eta_{\mathrm{s}}$, values, including when no phase crystallisation occurred, and the values of this property, ๆeff, determined from the fixed points.

Figure 11 shows the variation of the fixed viscosity points with heating rate determined by HSM. For the sake of simplicity, the figure includes only the values proposed by Pascual et al. [31] for the fixed viscosity points, as those assigned by this author display the least scatter. As in the third sintering section (Figure 6), the slope of these curves increased as the heating rate decreased. That is, glaze melting, which involved dissolution of the crystalline phases in the glass matrix, occurred more abruptly when the heating rate decreased. The figure also shows 
the effective sintering viscosity-temperature curves calculated at different heating rates. The viscosity peak was higher and shifted to lower temperatures as the heating rate decreased, as predicted by the glass crystallisation models [33] [34].

\section{Conclusions}

The main physico-chemical transformations that occurred during the firing of a commercial satin glaze were analysed in this study. The sintering behaviour and development of the crystal mass fractions, residual glass composition, and effective viscosity of the glaze are discussed, based on X-ray diffraction (XRD), hot stage microscopy (HSM), and thermal analysis (DTA) data. The sintering curves of this glaze displayed three stages: a first densification stage (stage I), a process halt, concurrent with glass particle crystallisation (stage II), and a second densification stage (stage III). The heating rate was verified to considerably influence the crystallisation process and sintering of the material, modifying the temperature range corresponding to each sintering curve stage. A two-step kinetic model was developed, step one corresponding to sintering stages I and II and step two corresponding to sintering stage III. The model satisfactorily describes the non-isothermal sinter-crystallisation obtained, at very different heating rates (between 0.5 and $60 \mathrm{~K} / \mathrm{min}$ ), of complex glaze compositions. The activation energy values obtained from the model for viscous flow sintering and for crystallisation were very similar, which means that the effect of temperature on the rate at which both processes developed was quite alike. The value of the crystallisation activation energy obtained by DTA was also very similar to that obtained from the model. This new kinetic model can be applied to many materials of a glass-ceramic nature that exhibit this behaviour in sintering. The developed model was used to calculate the effective sintering viscosity values of the glaze melt, which were compared with the effective viscosity data obtained by hot stage microscopy. The results obtained by the two methods exhibited good agreement. The calculated effective sintering viscosity provides a good understanding of the sintering behaviour of complex glaze compositions, enabling more rational design of these materials.

\section{References}

[1] J. L. Amorós, "Towards rational design of porcelain tile glazes," Advances in Science and Technology, vol. 92, p. 138-147, 2014. 
[2] J. L. Amorós, E. Blasco, M. P. Gómez-Tena, A. Moreno, E. Zumaquero and M. Galindo, "Glass-ceramic coatings on ceramic tiles: a novel sintering model," in Congreso Internacional de Ingerniería Química (ANQUE-ICCE 2012), 24-27 July 2012, Seville (Spain), 2012.

[3] J. L. Amorós, M. P. Gómez-Tena, A. Moreno, E. Zumaquero, E. Blasco and S. Sales, "Cristalización y sinterización de vidriados obtenidos a partir de fritas con alto contenido en metales divalentes (MO=30wt\%). Influencia de la velocidad de calentamiento," in IV Portuguese-Spanish Congress on Ceramics and Glasses, 16-18 November 2011, Aveiro (Portugal), 2011.

[4] A. Karamanov, L. Maccarini Schabbach, E. Karamanova, F. Andreola, L. Barbieri, B. Ranguelov, G. Avdeev and I. Lancelloti, "Sinter-crystallization in air and inert atmospheres of a glass from pre-treated municipal solid waste bottom ashes," Journal of Non-Crystalline Solids, vol. 389, p. 50-59, 2014.

[5] A. Karamanov, G. Taglieri and M. Pelino, "Sintering in nitrogen atmosphere of iron-rich glass-ceramics," Journal of American Ceramic Society, vol. 87, p. 1354-1357, 2004.

[6] A. Karamanov, L. Arrizza and S. Ergul, "Sintered material from alkaline basaltic tuffs," Journal of European Ceramic Society, vol. 29, p. 595-601, 2009.

[7] L. Lefebvre, L. Gremillard, J. Chevalier, R. Zenati and D. Bernache-Assolant, "Sintering behaviour of 45S5 bioactive glass," Acta Biomaterialia, vol. 4, p. 1894-1903, 2008.

[8] R. Müller, D. Thamm and M. Kirsch, "Sintering and crystallization of cordierite glass powders," Fortschritsberichte der DKG/CFI, Werkstoffe, Verfahrem, Anwendung, vol. 7, no. 1, p. 217-224, 1990.

[9] A. Karamanov, M. Aloisi and M. Pelino, "Sintering behaviour of a glass obtained from MSWI ash," Journal of the European Ceramic Society, vol. 25, p. 1531-1540, 2005.

[10] C. D. Doyle, "C. D. Doyle, "Series Approximations to the Equation of Thermogravimetric Data," Nature, vol. 207, p. 290-291, 1965.

[11] J. H. Flynn and L. A. Wall, "General treatment of the thermogravimetry of polymers," Journa of Research of the National Bureau of Standards - A. Physics and Chemistry, vol. 70A, no. 6, p. 487-523, 1966.

[12] A. Boccaccini, "Sintering of glass matrix composites containing Al2O3 platelet inclusions," Journal of Materials Science, vol. 29, p. 4273-4278, 1994. 
[13] R. E. Dutton and M. N. Rahaman, "Sintering creep, and electrical conductivity of model glass-matrix composites," Journal of the American Ceramic Society, vol. 75, no. 8, p. 21462154, 1992.

[14] H. E. Exner and E. A. Giess, "A stereology-based equation for isotropic shrinkage during sintering by viscous flow," Science and Sintering, p. 73-79, 1989.

[15] E. A. Giess, J. P. Fletcher and L. W. Herron, "Isothermal sintering of cordierite-type glass powders," Journal of the American Ceramic Society, vol. 67, no. 8, p. 549-552, 1984.

[16] E. A. Giess, C. F. Guerci, G. F. Walker and S. H. Wen, "Isothermal sintering of spheroidized cordierite-type glass powders," Journal of the American Ceramic Society, vol. 68, no. 12, pp. C-328-C-329, 1985.

[17] W. Hölland and G. Beall, in Glass-Ceramic technology, Westerville, The American Ceracmics Society, 2002.

[18] I. M. Krieger and T. J. Dougherty, "A mechanism for non-Newtonian flow in suspension of rigid spheres," Transactions of The Society of Rheology, vol. 3, p. 137-152, 1959.

[19] E. Blasco, Sinterización de compactos de vidrio y de composites vidrio-circón. Mecanismo y cinética del proceso, [Tesis doctoral]. Castellón. Universitat Jaume I. Departamento de Ingeniería química, 2017.

[20] R. Müller, M. Eberstein, S. Reinsch, W. A. Schiller, J. Deubener and A. Thiel, "Effect of rigid inclusions on sintering of low temperature co-fired ceramics," Physics and Chemistry of Glasses-B, vol. 48, no. 4, p. 259-266, 2007.

[21] J. L. Amorós, M. P. Gómez-Tena, A. Moreno, E. Blasco and M. Galindo, "Viscosidad efectiva de esmaltes. Efecto de la fracción volumétrica de cristales," in Poster LIII Congreso de la Sociedad Española de Cerámica y Vidrio (SECV 2013), Alcora, 2013.

[22] H. E. Kissinger, "Reaction kinetics in differential thermal analysis," Analytical Chemistry, vol. 29, no. 11, p. 1702-1706, 1957.

[23] T. Ozawa, "Kinetics of non-isothermal crystallization," Polymer, vol. 12, p. 150-158, 1971.

[24] H. M. Rietveld, "Line profiles of neutron powder-difraction peaks for structure refinement," Acta Crystallographica, vol. 22, no. 1, p. 151-152, 1967. 
[25] P. C. Panda, W. M. Mobley and R. Raj, "Effect of the heating rate on the relative rates of sintering and crystallization of glass," Journal of the American Ceramic Society, vol. 12, p. 2361-2364, 1989.

[26] A. R. Boccaccini, W. Stumpfe, D. M. R. Taplin and C. B. Ponton, "Densification and crystallization of glass powder compacts during constant heating rate sintering," Materials Science and Engineering A-Structural Materials Properties Microstructure and Processing, vol. 219, no. [1-2], p. 26-31, 1996.

[27] M. Tomellini, "Kolmogorov-Johnson-Mehl-Avrami kinetics for non-isothermal phase transformations rules by diffusional growth," Journal of Thermal Analysis and Calorimetry, vol. 116, p. 853-864, 2014.

[28] H. Scholze, "Influence of viscosity and surface tension on microscopy measurements on glasses," Ver. Dtsch. Keram., p. 63-68, 1962.

[29] J. M. Fernández-Navarro, El vidrio, Madrid: CSIC, 1991.

[30] M. J. Pascual, L. Pascual and A. Durán, "Determination of the viscosity-temperature curve for glasses on the basis of fixed viscosity points determined by hot stage microscopy," Physics and Chemistry of Glasses, vol. 42, no. 1, p. 61-66, 2001.

[31] M. J. Pascual and M. O. Prado, "A new method for determining fixed viscosity points of glasses," Physics and Chemistry of Glasses, vol. 46, no. 5, p. 512-520, 2005.

[32] V. I. Goleus, A. Y. Belyi, E. M. Sardak and Y. I. Belyi, "Calculation of the surface tension of molten borosilicate glasses," Glass and Ceramics, vol. 53, no. 8, p. 226-228, 1996.

[33] D. W. Henderson, "Thermal-analysis of nonisothermal crystallization kinetics in glass forming liquids," Journal of Non-Crystalline Solids, vol. 30, no. 3, p. 301-315, 1979.

[34] M. C. Weinberg, "On the analysis of nonisothermal thermoanalytical crystallization experiments," Journal of Non-Crystalline Solids, vol. 127, no. 2, p. 151-158, 1991.

[35] J. L. Amorós, E. Blasco, M. P. Gómez-Tena, A. Moreno, E. Zumaquero and M. Galindo, "Glass-ceramic coatings on ceramic tiles: a novel sintering model," in Congreso Internacional de Ingeniería Química (ANQUE-ICCE 2012), 24-27 July 2012, Seville (Spain), 2012.

[36] A. Karamanov, G. Taglieri and M. Pelino, "Sintering in nitrogen atmosphere of iron-rich glass-ceramics," Journal of the American Ceramic Society, vol. 87, p. 1354-1357, 2004. 
[37] A. Karamanov, L. Arrizza and S. Ergul, "Sintered material from alkaline basaltic tuffs," Journal of the European Ceramic Society, vol. 29, p. 595-601, 2009.

[38] R. Müller, D. Thamm and M. Kirsch, "Sintering and crystallization of cordierite glass powders," Fortschrittsberichte der DKG/CFI, Werkstoffe, Verfahren, Anwendung, vol. 7, no. 1, p. 217-224, 1990.

[39] J. H. Flynn and L. A. Wall, "General treatment of the thermogravimetry of polymers," Journal of Research of the National Bureau of Standards - A. Physics and Chemistry, vol. 70A, no. 6, p. 487-523, 1966.

[40] W. Hölland and G. Beall, in Glass-ceramic technology, Westerville, The American Ceramic Society, 2002.

[41] E. Blasco, Sinterización de compactos de vidrio y de composites vidrio-circón. Mecanismo y cinética del proceso, PhD Dissertation. Castellón (Spain). Universitat Jaume I. Department of Chemical Engineering., 2017.

[42] J. L. Amorós, M. P. Gómez-Tena, A. Moreno, E. Blasco and M. Galindo, "Viscosidad efectiva de esmaltes. Efecto de la fracción volumétrica de cristales," in Poster LIII Congreso de la Sociedad Española de Cerámica y Vidrio (SECV 2013), 23-25 Octubre 2013, Alcora (Spain), 2013.

[43] H. M. Rietveld, "Line profiles of neutron powder-diffraction peaks for structure refinement," Acta Crystallographica, vol. 22, no. 1, p. 151-152, 1967.

[44] D. W. Henderson, "Thermal analysis of non-isothermal crystallization kinetics in glass forming liquids," Journal of Non-Crystalline Solids, vol. 30, no. 3, p. 301-315, 1979.

[45] M. C. Weinberg, "On the analysis of non-isothermal thermoanalytical crystallization experiments," Journal of Non-Crystalline Solids, vol. 127, no. 2, p. 151-158, 1991. 
Table 1. Composition (wt\%) of the studied commercial glaze. 
Table 2. Glaze mass fractions obtained by Rietveld analysis of the X-ray diffraction diagram on heating at $25 \mathrm{~K} / \mathrm{min}$ to different temperatures. 
Table 3. Influence of the heating rate, a, on the values of the following temperatures:

crystallisation onset, $T_{x}$; peak crystallisation, $T_{p}$; melting onset, $T_{i f}$; sintering onset stage $\mathrm{I}, \mathrm{T}_{\mathrm{i}}(\mathrm{I})$; sintering end stage $\mathrm{I}, \mathrm{T}_{\mathrm{f}}(\mathrm{I})$; sintering onset stage $\mathrm{III}, \mathrm{T}_{\mathrm{i}}(\mathrm{III})$; and sintering end stage III, $\mathrm{T}_{\mathrm{f}}(\mathrm{III})$. (Values obtained by DTA and HSM). 
Table 4. Values of the sintering kinetic parameters with concurrent crystallisation. 
Figure 1. Relationship between the glass particle surface fraction free of crystals, $\alpha_{g}$, and relationship of crystal size, $2 r_{c}$, to the average distance between the nuclei, $\ell$. a) Idealised distribution of nuclei and b) Comparison of the Müller relationship [8] with Eq. 3 for distribution a). 
Figure 2. Phase variation with temperature at $a=25 \mathrm{~K} / \mathrm{min}$, obtained from Table 2. 
Figure 3. SEM micrograph of the fired glaze at $1140^{\circ} \mathrm{C}$. Heating rate: $a=25 \mathrm{~K} / \mathrm{min}$. (Ab=albite; $\mathrm{An}=$ anorthite; $\mathrm{Hy}=$ hyalophane; Or=anorthoclase; $\mathrm{Zr}=z i r c o n i a ; g=g l a s s)$. 
Figure 4. Glaze sintering and crystallisation. Heating rate: a=25K/min. (Sintering stages I, II, and III; $T_{g}, T_{x}, T_{p}$, and $T_{i f}$, transformation, crystallisation onset, peak crystallisation, and melting onset temperatures, respectively). 
Figure 5. Estimated residual glass composition at different temperatures. 
Figure 6. Effect of the heating rate, a, on the sintering curve, $X$ vs. T. Fit of the experimental data to the developed model (Eq. 21). 
Figure 7. Determination of the crystallisation activation energy, $E_{c r}$, by the Kissinger method [22]. 
Figure 8. Determination of the Avrami parameter, n, by the Ozawa method [23]. 
Figure 9. Variation of $Q_{3}(a)$ and $k_{3}(a)$ (Eq. 21) as a function of the heating rate, a. 
Figure 10. Fixed viscosity points assigned by different authors. Glaze effective sintering viscosity, with and without crystallisation, calculated from Eq. 25. 
Figure 11. Effect of the heating rate, a, on glaze effective sintering viscosity and fixed viscosity points suggested by Pascual et al. [31]. 